\title{
Revision_1 \\ On the crystal structure and compressional behaviour of talc: a mineral of interest in petrology and material science
}

G. Diego Gatta, Marco Merlini, Giovanni Valdrè, Hanns-Peter Liermann, Gwilherm Nénert, André Rothkirch, Volker Kahlenberg, Alessandro Pavese

Running title: $\mathrm{H} P$ crystal chemistry of talc

\author{
Abstract \\ Introduction \\ Experimental methods \\ Single-crystal $X$-ray and neutron structure refinement \\ Elastic behavior of talc at high pressure \\ Discussion and conclusions \\ Acknowledgements \\ References \\ Figures/Tables
}

Corresponding author: G. Diego GATTA

Dip. Scienze della Terra

Universita' degli Studi di Milano

Via Botticelli, 23

I-20133 Milano, Italy

Tel. +3902503 15607

Fax +390250315597

E-Mail: diego.gatta@unimi.it

Operating system: Windows XP

(To be submitted to Physics and Chemistry of Minerals) 


\title{
On the crystal structure and compressional behaviour of talc: a mineral of interest in petrology and material science
}

\author{
1,2 G. Diego Gatta, ${ }^{1}$ Marco Merlini, ${ }^{3}$ Giovanni Valdrè, ${ }^{4}$ Hanns-Peter Liermann, \\ ${ }^{5}$ Gwilherm Nénert, ${ }^{4}$ André Rothkirch, ${ }^{6}$ Volker Kahlenberg, ${ }^{1,2}$ Alessandro Pavese \\ ${ }^{1}$ Dipartimento di Scienze della Terra, Università degli Studi di Milano, \\ Via Botticelli 23, I-20133 Milano, Italy \\ ${ }^{2}$ CNR-Istituto per la Dinamica dei Processi Ambientali, Milano, Italy \\ ${ }^{3}$ Dipartimento di Scienze della Terra e Geologico-Ambientali, Università di Bologna, P. Porta San Donato 1, I-40126, Bologna, Italy \\ ${ }^{4}$ DESY, HASYLAB, PETRA III, Notkestr. 85, D-22607 Hamburg, Germany \\ ${ }^{5}$ Institut Laue-Langevin, B.P. 156, F-38042 Grenoble Cedex 9, France \\ ${ }^{6}$ Institut für Mineralogie und Petrographie, Universität Innsbruck, Innrain 52, A-6020 Innsbruck, Austria
}

\begin{abstract}
The crystal structure of a natural triclinic talc (1Tc polytype) [with composition: $\left.\left(\mathrm{Mg}_{2.93} \mathrm{Fe}_{0.06}\right)_{\Sigma 2.99}\left(\mathrm{Al}_{0.02} \mathrm{Si}_{3.97}\right)_{\Sigma 3.99} \mathrm{O}_{10}(\mathrm{OH})_{2.10}\right]$ has been investigated by single-crystal X-ray diffraction at $223 \mathrm{~K}$ and $170 \mathrm{~K}$ and by single-crystal neutron diffraction at $20 \mathrm{~K}$. Both the anisotropic X-ray refinements (i.e. at $223 \mathrm{~K}$ and $170 \mathrm{~K}$ ) show that the two independent tetrahedra are only slightly distorted. For the two independent Mg-octahedra, the bond distances between cation-hydroxyl groups are significantly shorter than the others. The ditrigonal rotation angle of the six-membered ring of tetrahedra is modest $\left(\alpha \sim 4^{\circ}\right)$. The neutron structure refinement shows that the hydrogen bonding scheme in talc consists of one donor site and three acceptors (i.e. trifurcated configuration), all the bonds having $\mathrm{O} \cdots \mathrm{O} \leq 3.38 \AA, \mathrm{H}^{\cdots} \mathrm{O} \sim 2.8 \AA$, and $\mathrm{O}-\mathrm{H} \cdots \mathrm{O} \sim 111-116^{\circ}$. The three acceptors belong to the six-membered ring of tetrahedra juxtapposed to the octahedral sheet. The vibrational regime of the proton site appears being only slightly anisotropic.

The elastic behaviour of talc was investigated by means of in situ synchrotron single-crystal diffraction up to $16 \mathrm{GPa}$ (at room temperature) using a diamond anvil cell. No evidence of phase transition has been observed within the pressure-range investigated. $P-V$ data fit, with an isothermal third-order Birch-Murnaghan Equation of State, results: $V_{0}=454.7(10) \AA^{3}, K_{\mathrm{T} 0}=56(3) \mathrm{GPa}$ and $K^{\prime}=$ 5.4(7). The "Eulerian finite strain" vs "normalized stress" plot yields: $F e(0)=56(2) \mathrm{GPa}$ and $K$ '= 5.3(5). The compressional behavior of talc is strongly anisotropic, as reflected by the axial compressibilities (i.e. $\beta(a): \beta(b): \beta(c)=1.03: 1: 3.15)$ as well as by the magnitude and orientation of the unit-strain ellipsoid (with $\varepsilon_{1}: \varepsilon_{2}: \varepsilon_{3}=1: 1.37: 3.21$ ). A comparison between the elastic parameters of talc obtained in this study with those previously reported is carried out.
\end{abstract}

Keywords: talc, phyllosilicates, neutron diffraction, synchrotron diffraction, high-pressure, compressibility. 


\section{Introduction}

Talc is a phyllosilicate, with ideal chemical formula $\mathrm{Mg}_{3} \mathrm{Si}_{4} \mathrm{O}_{10}(\mathrm{OH})_{2}$ (Bailey 1988). It occurs mainly as a natural product of metamorphism or hydrothermal alteration of Mg-rich ultramafic rocks (Evans and Guggenheim 1988). The petrological investigation of peridotites suggested talc as an important phase in the oceanic crust (e.g. Cannat 1993; Trommsdorff et al. 1998; Mével 2003). Talc is expected to play a significant role as a transport vehicle for water into the mantle via subduction zones (e.g. Poli and Schmidt 2002), as it contains $\sim 5 \mathrm{wt} \%$ of $\mathrm{H}_{2} \mathrm{O}$. Metasediments involved in subduction processes are supposed to transform, in response to applied $P / T$, to a talc-bearing assemblage (e.g. Mysen et al. 1998). In addition, in mantle wedge talc forms from the breakdown of antigorite resulting in talc + forsterite $+\mathrm{H}_{2} \mathrm{O}$ (Evans et al. 1976). Several studies highlighted how talc acts as precursor of the so-called $10 \AA$ phase, a dense $\mathrm{H}_{2} \mathrm{O}$-bearing phyllosilicate considered as one of the water carrier in subduction zones (e.g. Chinnery et al. 1999; Fumagalli et al. 2001; Comodi et al. 2005; Gleason et al. 2008). The decomposition of talc to coesite + enstatite $+\mathrm{H}_{2} \mathrm{O}$ was observed at 3-5 GPa and 700-800 ${ }^{\circ} \mathrm{C}$ (Pawley and Wood 1995).

Talc is also one of the most important industrial minerals, because of its low coefficient of friction (i.e. 0.2), chemical inertness and hydrophobicity. It is widely used in several technological applications: paper coating, paint, ceramics, and polymer industries. In the automotive industry, for example, talc is added to polymers to stabilize and harden automobile spare parts (e.g. fenders, dashboards, steering wheels). The industrial applications of talc led to numerous investigation of its deformational behavior by compaction and shear even at high-temperature (e.g. Dellisanti and Valdrè 2008, 2010; Dellisanti et al. 2009). World talc production in 2011 was estimated to be $7,500,000$ tons.

Despite the important role talc plays in petrological or industrial processes, several questions about the crystal chemistry and the thermodynamic properties of this mineral are still unanswered. The crystal structure of talc was first described by Gruner (1934) (monoclinic $C 2 / c$, with $a \sim 5.26 \AA$, $b \sim 9.10 \AA, c \sim 18.81 \AA$, and $\beta \sim 100.0^{\circ}$ ). Later, the structure of talc was refined in different space groups (i.e. $C$, Hendricks 1938; $C \overline{1}$, Rayner und Brown 1973; $P \overline{1}$ and $C \overline{1}$, Perdikatsis and Burzlaff 1981), starting from the structure model of Gruner (1934). The crystal structure of talc consists of a sheet of linked $\left[\mathrm{MgO}_{4}(\mathrm{OH})_{2}\right]$ octahedra ("O ") sandwiched between two sheets of $\mathrm{SiO}_{4}$ tetrahedra ("T") combined to six-member rings, giving the so-called "T-O-T" layered structure (Fig. 1). Al or Fe can be present in natural talc $(\leq 2 \mathrm{wt} \%$ ). The charge-neutral T-O-T layers are held together by relatively weak van der Waals attractive forces, resulting in the extreme softness of this mineral when compared to other phyllosilicates. Crystals of talc are affected by polytypism and stacking disorder, as often observed in phyllosilicates. Polytype derivations for talc using the Dornberger- 
Shiff OD structure theory have been developed by Durovič and Weiss (1983) and Weiss and Durovič (1984), with 10 non-equivalent theoretical polytypes. The position of the (unique) proton site in the crystal structure of talc (1Tc polytype) was suggested by Perdikatsis and Burzlaff (1981) on the basis of single-crystal X-ray diffraction, with the $\mathrm{OH}$ group of the octahedral sheet positioned near the centers of the six-member silicate rings (Fig. 1). The only X-ray structure refinement of talc based on modern crystallographic standards is that of Perdikatsis and Burzlaff (1981) that has left some unanswered questions, especially regarding the proton position, its anisotropic thermal regime and the hydrogen-bonding scheme. No neutron diffraction experiment devoted to talc has been performed to date.

Additional questions concern the high-pressure $(\mathrm{H} P)$ stability field and the compressional behavior of talc, since results in the literature are conflicting. Recent studies, based on in situ synchrotron powder diffraction data in diamond anvil cell and infra-red spectroscopy, suggested a phase transformation of talc to a so-called "talc-II" phase at pressure in excess of 4-6 GPa and at room- $T$ (Parry et al. 2007; Gleason et al. 2008). However, no description of the structure of the "talc-II" phase was provided and the diffraction pattern of the talc-II was indexed with the same symmetry as that of the talc-I (Gleason et al. 2008). The range of the elastic parameters of talc (i.e. axial and volume bulk moduli, $P$-derivative of the bulk moduli) at room- $T$ reported in the literature, obtained by Murnaghan (Murnaghan 1937) or Birch-Murnaghan (Birch 1947) equation of state fit, is surprisingly broad: the bulk moduli range between 32 and $55 \mathrm{GPa}$, their $P$-derivative from 6 to 18 (Pawley et al. 1995, 2002; Stixrude 2002; Gleason et al. 2008; Mainprice et al. 2008).

The aim of the present study is twofold:

1) A re-investigation of the crystal structure of a natural talc at ambient conditions and at low- $T$ (useful to reduce thermal libration motion, which can be significant in this class of materials, Gatta et al. 2011a) by means of single-crystal X-ray and neutron diffraction, in order to provide the reliable location of the proton site, its vibrational regime and the real topological configuration of the $\mathrm{OH}$-group, for a full description of the atomic relationship via the H-bonds;

2) A re-investigation of the compressional behavior of talc by in situ single-crystal synchrotron diffraction in a diamond anvil cell under hydrostatic conditions.

A comparison between the elastic parameters of talc and those of other phyllosilicates is carried out. 


\section{Experimental methods}

A natural sample of talc from the methamorphic complex of Val di Vizze (Pfitschtal), Bolzano, Trentino-Alto Adige (Südtirol), Italy, was used in this study (Gartner and Gartner 2002, Barnes et al. 2004 and reference therein).

Electron microprobe analysis of talc in wavelength dispersive mode (EMPA-WDS) was performed on several crystals (optically free of defect or zoning) using a Jeol JXA-8200 microprobe. Major and minor elements were determined at $15 \mathrm{kV}$ accelerating voltage and $10 \mathrm{nA}$ beam current with a counting time of 20 seconds. The standards employed were: albite ( $\mathrm{Al}, \mathrm{Si}, \mathrm{Na}$ ), microcline $(\mathrm{K})$, anorthite $(\mathrm{Ca})$, fayalite $(\mathrm{Fe})$, and forsterite $(\mathrm{Mg})$. The crystals appear to be chemically homogeneous and averaging 5 points analyses we obtained: $\mathrm{SiO}_{2} 62.69 \mathrm{wt} \%, \mathrm{Al}_{2} \mathrm{O}_{3}$ $0.19 \mathrm{wt} \%, \mathrm{FeO} 1.07 \mathrm{wt} \%, \mathrm{MgO} 31.07 \mathrm{wt} \%$ and $\mathrm{H}_{2} \mathrm{O} 4.98 \mathrm{wt} \%$ (by difference), resulting in the following chemical formula: $\left(\mathrm{Mg}_{2.93} \mathrm{Fe}_{0.06}\right)_{\Sigma 2.99}\left(\mathrm{Al}_{0.02} \mathrm{Si}_{3.97}\right)_{\Sigma 3.99} \mathrm{O}_{10}(\mathrm{OH})_{2.10}$.

The quality of a significant number of crystals (about 35) was examined with a Xcalibur Oxford Diffraction diffractometer equipped with a CCD, in order to find crystals of talc suitable for the X-ray and neutron diffraction experiments. The majority of crystals gave streaked reflections, suggesting stacking disorder, frequently observed in phyllosilicates (e.g. Bailey 1988; Evans and Guggenheim 1988; Guggenheim and Eggleton 1987, 1988; Nespolo and Ferraris 2001; Nespolo and Durovič 2002). The diffraction patterns of a few crystals only showed the absence, at a significant level, of stacking disorder; such crystals were then selected for the in house (crystal sizes of $\left.\sim 0.180 \times 0.150 \times 0.04 \mathrm{~mm}^{3}\right)$, synchrotron $\left(\sim 0.05 \times 0.05 \times 0.005 \mathrm{~mm}^{3}\right)$ and neutron diffraction experiment $\left(\sim 3.5 \times 2.8 \times 0.8 \mathrm{~mm}^{3}\right)$, respectively. Diffraction patterns of all crystals collected at room conditions were successfully indexed in the $C \overline{1}$ space group, with $a \sim 5.29 \AA, b \sim 9.17 \AA, c \sim 9.48$ $\AA, \alpha \sim 90.9^{\circ}, \beta \sim 99.6^{\circ}$ and $\gamma \sim 90.1^{\circ}$ (1Tc polytype), according to Perdikatsis and Burzlaff (1981).

Single-crystal X-ray diffraction data were collected at $223 \mathrm{~K}$ and at $170 \mathrm{~K}$ using an Oxford Diffraction Gemini Ultra diffractometer, equipped with a Ruby CCD detector and graphite monochromator, operating at $50 \mathrm{kV}$ and $40 \mathrm{~mA}$ with $\mathrm{MoK \alpha}$ radiation. Low temperature data collections were performed with the crystal cooled by an Oxford Cryosystems 700 series Plus openflow nitrogen gas device (temperature stability better than $0.2 \mathrm{~K}$, temperature absolute uncertainty within $2 \mathrm{~K}$ at the crystal position). A combination of $\omega / \varphi$ scans was used to maximize data coverage and redundancy, with $1^{\circ}$ scan width, $30 \mathrm{~s}$ frame exposure time and maximum $2 \theta$ of $\sim 70^{\circ}$ (Table 1). The diffraction patterns collected at $223 \mathrm{~K}$ and $170 \mathrm{~K}$ were successfully indexed with a $C$-centered triclinic lattice (Table 1), showing a substantial absence of stacking disorder. Lorentz-polarization corrections were applied to the two datasets using CrysAlis software (Agilent 2012). Further details pertaining to the data collection strategies are given in Table 1. 
Single-crystal neutron diffraction data were measured at a temperature of $20 \mathrm{~K}$ on the fourcircle diffractometer D9 at the Institut Laue-Langevin, Grenoble, in a beam of wavelength $0.8381(2) \AA ̊$ obtained by reflection from a $\mathrm{Cu}(220)$ monochromator. D9 is equipped with a small two-dimensional area detector (Lehmann et al. 1989), which for this measurement allowed optimal delineation of the peak from the background. Reflections of the type $\pm h, \pm k, \pm l$ to $2 \theta_{\max }=61^{\circ}$ were scanned, out of which 635 were "observed" (Table 1). For all data, background corrections following Wilkinson et al. (1988) and Lorentz corrections were applied. Absorption corrections were made by Gaussian integration (Coppens et al. 1965) using the calculated attenuation coefficients, taking into account the wavelength dependence of the absorption for hydrogen (Howard et al. 1987). The unit-cell constants, obtained by least-squares matching of the observed and calculated centroids of more than 200 strongest reflections, are: $a=5.299(3) \AA, b=9.165(4) \AA$, $c=9.484(7) \AA, \alpha=90.76(5)^{\circ}, \beta=100.39(5)^{\circ}$ and $\gamma=90.16(4)^{\circ}$, with a $C$-centered lattice.

$\mathrm{H} P$-synchrotron X-ray single-crystal diffraction experiments were performed at the beamline P02.2 (Extreme Conditions Beamline) at DESY/PETRA III, using X-rays with an energy of $42.7 \mathrm{keV}\left(0.29036 \AA\right.$ wavelength) and a focusing spot of $\sim 8.5(\mathrm{H})$ x $1.8(\mathrm{~V}) \mu \mathrm{m}^{2}$ originating from a Compound Refractive Lenses (CRL) system consisting of 240 Be lenses with a radius of 50 $\mu \mathrm{m}$ (400 $\mu \mathrm{m}$ beam acceptance) and a focal length of $1221 \mathrm{~mm}$. A platy single crystal of talc $(\sim 50 \mathrm{x}$ $50 \times 5 \mathrm{~m}^{3}$ ) was loaded in a symmetric diamond anvil cell (DAC), equipped with Boehler Almax design diamonds/seats with a $70^{\circ}$ opening and $300 \mu \mathrm{m}$ culets size. The perfect cleavage of talc on $\{001\}$ allowed one orientation only, with the $a b$-plane perpendicular to the DAC axis. A $250 \mu \mathrm{m}$ thick rhenium gasket was pre-indented to $50 \mu \mathrm{m}$ and then drilled with $200 \mu \mathrm{m}$ hole, in which the crystal of talc along with some calibrated ruby spheres for pressure determination (Mao et al. 1986) were located. Neon was used as hydrostatic pressure transmitting medium (Klotz et al. 2009). Pressure was increased with an automated pressure driven system and measured with the online ruby/alignment system. Diffraction images were acquired on a PerkinElmer XRD 1621 flat panel detector, using an in house script for collecting step-scan diffraction images. Sample to detector distance (402.34 mm) was calibrated using a $\mathrm{CeO}_{2}$ standard (NIST 674a). The images were then converted with an in house software script to conform to the standard format of the program CrysAlis (Agilent 2012). The diffraction data were first collected with the crystal in the DAC and without any $P$-medium (i.e. ambient pressure). A pure $\omega$-scan $\left(-28 \leq \omega \leq+28^{\circ}\right)$, with a step size of $1^{\circ}$ and an exposure time of $5 \mathrm{~s} /$ frame was used. Bragg peaks were then indexed and their intensities were integrated and corrected for Lorentz-polarization (Lp) effects, using the CrysAlis package (Agilent 2012). The reflection conditions were consistent with those of the space group $C \overline{1}$. No significant evidence of stacking disorder was observed. However, any attempt at performing a 
structure refinement was unsuccessful, likely due to the low number of "observed" reflections (i.e. with $\left.F_{\mathrm{O}}>4 \sigma\left(F_{\mathrm{O}}\right)\right)$. HP data collections up to $15.5(1) \mathrm{GPa}$ (the hydrostatic limit of neon, according to Klotz et al. 2009) were performed. No evidence of phase transitions were observed within the $P$ range investigated; all the $\mathrm{H} P$ diffraction patterns were successfully indexed in the $C \overline{1}$ space group.

\section{$\mathrm{X}$-ray and neutron structure refinements}

The X-ray anisotropic structural refinements of talc at $223 \mathrm{~K}$ and $170 \mathrm{~K}$ were conducted using the SHELX-97 software (Sheldrick 1997, 2008). A preliminary data treatment based on the statistics of distributions of the normalized structure factors $\left(E^{\prime} s\right)$ suggested that the structure of talc is centrosymmetric. The refinement was conducted using as starting structure model that of Perdikatsis and Burzlaff (1981). Neutral atomic scattering factors of $\mathrm{Mg}, \mathrm{Fe}, \mathrm{Si}, \mathrm{O}$ and $\mathrm{H}$ from the International Tables for Crystallography (Wilson and Prince 1999) were used. In the first cycles of refinements (1) a $\mathrm{Mg} / \mathrm{Fe}$ mixed scattering curve was used to model the octahedral $M 1$ and $M 2$ sites; (2) the Si scattering curve was used to model the tetrahedral $T 1$ and $T 2$ sites (Table 2), and (3) no proton site was located. However, no improvement of the figures of merit of the refinements, with respect to those obtained by the X-ray scattering curve of $\mathrm{Mg}$ only at the octahedral sites, was observed. After the first cycles of refinement, a significant residual in the difference-Fourier map of the electron density was found at the fractional coordinates $\sim 0.80, \sim 0.65, \sim 0.29\left(\Delta \rho \sim 2.8 e^{-} / \AA^{3}\right)$, suggesting a stacking disorder, often occurring in this class of materials (e.g. Bailey 1988, Guggenheim and Eggleton 1988, Nespolo and Ferraris 2001; Nespolo and Ďurovič 2002, Gatta et al. 2011b). Thus, a "virtual" tetrahedral site, labelled as $T$ ' and treated as partially occupied by $\mathrm{Si}$, was added to the structure model and refined isotropically (sof $\sim 10 \%$, Table 2). The proton site was located on the basis of the maxima found in the difference-Fourier map of the electron density (expected to be bonded to the $\mathrm{O} 2$ oxygen site, Table 2), and refined isotropically. When convergence was achieved, no residual peak larger than $+2.1 /-1.3 e^{-} / \AA^{3}$ was present in the final difference-Fourier synthesis (Table 1) and the variance-covariance matrix showed no significant correlation among the refined parameters. Both the refinements (i.e. at $223 \mathrm{~K}$ and $170 \mathrm{~K}$ ) converge with an agreement index of $R_{1} \sim 7 \%$. Further details pertaining to the X-ray structure refinement are given in Table 1. Site positions and displacement parameters are given in Tables 2 and 3. Bond distances and other relevant structural parameters are listed in Table 4.

The X-ray structure was used as starting structure model for the neutron refinement. The neutron scattering lengths of $\mathrm{Mg}, \mathrm{Fe}, \mathrm{Si}, \mathrm{O}$, and $\mathrm{H}$ have been used according to Sears (1986). The secondary isotropic extinction was corrected by Larson's formalism (1967), as implemented in the 
SHELXL-97 package. Due to the low number of "observed" reflections, along with a high correlation of the anisotropic displacement parameters, the neutron refinement was conducted with isotropic displacement parameters for all the atomic sites. Only the proton site was refined anisotropically. Also in this case, any attempt to refine the fraction of Fe at the M1 and M2 octahedral sites was unsuccessful. In this case, the "virtual" tetrahedral site (i.e. T', in the X-ray refinement, Table 2) due to staking disorder was not observed. When the convergence was achieved, the variance-covariance matrix showed no significant correlation among the refined parameters and at the end of the last cycle of refinement no peak larger than $+3.2 /-2.7 \mathrm{fm} / \AA^{3}$ was present in the final difference-Fourier map of the nuclear density (Table 1). The final agreement index $\left(R_{1}\right)$ was $\sim 14 \%$ for 42 refined parameters and 635 unique reflections with $F_{0}>4 \sigma\left(F_{0}\right)$ (Table 1). Site coordinates and displacement parameters are reported in Tables 2 and 3. Bond lengths and and other relevant structural parameters are listed in Table 4.

\section{Elastic behavior of talc at high-pressure}

The evolution of the unit-cell constants of talc with pressure (data listed in Table 5) is shown in Fig. 2. The behavior appears to be monotonic, without any clear evidence of phase transition or significant change in the compressional mechanisms, within the $P$-range investigated. The $\alpha$ angle appears to be almost unaffected by the applied pressure, the $\gamma$ angle shows only a slight increases within the $P$-range investigated, whereas the $\beta$ angle tends to increase significantly toward a saturation at $P>7-8 \mathrm{GPa}$ (Fig. 2). The unit-cell of talc tends, therefore, to be more distorted in response to hydrostatic pressure.

Unit-cell volume vs. $P$ were fitted with a Murnaghan (M-EoS) and with a third-order BirchMurnaghan Equation of State (III-BM-EoS) (Murnaghan 1937; Birch 1947) using the EOS-FIT5.2 program (Angel 2001). The fit was performed using the data weighted by the uncertainties in $P$ and $V$. The refined elastic parameters are: $V_{0}=454.7(9) \AA^{3}, K_{\mathrm{T} 0}=57(3) \mathrm{GPa}$ and $K^{\prime}=4.9(5)$ for a M-EoS fit and $V_{0}=454.7(10) \AA^{3}, K_{\mathrm{T} 0}=56(3) \mathrm{GPa}$ and $K^{\prime}=5.4(7)$ for a III-BM-EoS fit, respectively. The confidence-ellipse referred to the $68.3 \%, 95.4 \%$ and $99.7 \%$ confidence-levels, respectively $\left(\Delta \chi^{2}\right.$ $\left.=2.30, \pm 1 \sigma ; \Delta \chi^{2}=6.17, \pm 2 \sigma ; \Delta \chi^{2}=11.8, \pm 3 \sigma\right)$, were calculated using the variance-covariance matrices of $K_{\mathrm{T} 0}$ and $K^{\prime}$ obtained from the least-squares procedure for the III-BM-EoS fit (Angel 2000). The ellipses are elongated with negative slope (Fig. 3), showing a negative correlation of the parameters $K_{\mathrm{T} 0}$ and $K^{\prime}$. 
The evolution of the "Eulerian finite strain" vs "normalized stress" ( $f e-F e$ plot; Angel 2000) is shown in Fig. 2. The intercept value obtained by a weighted linear regression through the data points is $\mathrm{Fe}(0)=56(2) \mathrm{GPa}$, the slope of the regression line leads to a $K^{\prime}$ value of 5.3(5).

In order to describe the elastic anisotropy, the axial bulk moduli were calculated with a "linearized" III-BM-EoS (Angel 2000), accounting for uncertainties in $P$ and length. The refined elastic parameters are: $a_{0}=5.309(6) \AA, K_{\mathrm{T} 0}(a)=95(13) \mathrm{GPa}$ and $K^{\prime}(a)=5.9(21)$ for the $a$-axis; $b_{0}=$ 9.216(9) $\AA, K_{\mathrm{T} 0}(b)=99(5) \mathrm{GPa}$ and $K^{\prime}(b)=4$ (fixed) for the $b$-axis; $c_{0}=9.434(22) \AA, K_{\mathrm{T} 0}(c)=$ $31(4)$ with $K^{\prime}(c)=4.6(8)$ for the $c$-axis $\left[\beta(a)=1 / 3 K_{\mathrm{T} 0}(a)=0.0035(4) \mathrm{GPa}^{-1} ; \beta(b)=1 / 3 K_{\mathrm{T} 0}(b)=\right.$ $\left.0.0034(2) \mathrm{GPa}^{-1} ; \beta(c)=1 / K_{\mathrm{T} 0}(c)=0.0107(12) \mathrm{GPa}^{-1} ; \beta(a): \beta(b): \beta(c)=1.03: 1: 3.15\right]$.

The magnitude and orientation of the principal unit-strain coefficients between room pressure and the maximum $P$ achieved $(\Delta P=15.5 \mathrm{GPa})$, derived on the basis of the finite Eulerian strain tensor, were calculated with the Win_Strain software (Angel 2011). We have chosen the following Cartesian axial system: $x / / a^{*}$ and $z / / c$. The strain ellipsoid is oriented as follows: $\varepsilon_{1}=-0.0304(2) \mathrm{GPa}^{-}$ ${ }^{1}, \varepsilon_{2}=-0.0416(2) \mathrm{GPa}^{-1}$, and $\varepsilon_{3}=-0.0975(16) \mathrm{GPa}^{-1} ; \varepsilon_{1} \angle a=152.7(6)^{\circ}, \quad \varepsilon_{1} \angle b=64.8(8)^{\circ}$, and $\varepsilon_{1} \angle c$ $=69.1(5)^{\circ} ; \varepsilon_{2} \angle a=66.0(8)^{\circ}, \varepsilon_{2} \angle b=25.2(7)^{\circ}$, and $\varepsilon_{2} \angle c=100.1(3) ; \varepsilon_{3} \angle a=77.7(6)^{\circ}, \quad \varepsilon_{3} \angle b=8$ $9.8(5)^{\circ}$, and $\varepsilon_{3} \angle c=23.4(6)^{\circ}$. The orientation of the strain ellipsoid is shown in Fig. 1. Despite the pseudo-monoclinic lattice of talc, the angle between $\varepsilon_{2}$ and [010] differs significantly from 0 (i.e. $\left.\varepsilon_{2} \angle b=25.2(7)^{\circ}\right)$. The elastic behaviour of talc described on the basis of the unit-strain coefficients between 0.0001 and $15.5 \mathrm{GPa}$ is significantly anisotropic, with $\varepsilon_{1}: \varepsilon_{2}: \varepsilon_{3}=1: 1.37: 3.21$.

\section{Discussion and conclusions}

This is the first experiment in which the crystal structure of talc is described on the basis of single-crystal X-ray and neutron diffraction, and its compressional behavior studied by in situ single-crystal synchrotron diffraction with a diamond anvil cell.

The chemical analysis reveals that the sample of talc used in this study approaches the ideality, with only a low amount of $\mathrm{Fe}$ (i.e. 0.06 a.p.f.u.) and $\mathrm{Al}$ (i.e. 0.02 a.p.f.u.), likely replacing $\mathrm{Mg}$ and $\mathrm{Si}$ at the octahedral and tetrahedral sites, respectively.

Finding single-crystals of talc suitable for X-ray and, in particular, for neutron diffraction experiments was a challenge. The single-crystal X-ray and neutron structure refinements provide a structure model which is comparable to those previously reported for the triclinic 1Tc polytype (e.g. Rayner and Brown 1973, Perdikatsis and Burzlaff 1981). Both the X-ray refinements (i.e. at 223 and $170 \mathrm{~K}$ ) show that the two independent tetrahedra are only slightly distorted (Table 4), as previously observed (Rayner and Brown 1973, Perdikatsis and Burzlaff 1981). For the two 
independent Mg-octahedra, the bond distances between cation-hydroxyl groups (i.e. M1-O2, M2O2, and M2-O2', Table 4) are significantly shorter than the others. As expected, the site displacement of the "bridging" oxygen sites $O 1, O 2$ and $O 3$ appear being systematically lower than those of the "non-bridging" O4, O5 and O6 sites, at any temperature (Tables 2 and 3). The ditrigonal rotation angle of the six-membered ring of tetrahedra in talc is modest $\left(\alpha \sim 4^{\circ}\right.$, Table 4$)$. If we consider the neutron structure refinement, the hydrogen bonding scheme in talc consists of one donor site (i.e. O2, Tables 2 and 4) and three acceptors (i.e. O4, O5 and O6), with a trifurcated configuration as shown in Fig. 1, all the bonds having $O 2 \cdots O \leq 3.38 \AA, H^{\cdots} O \sim 2.8 \AA$, and $O 2$ $H^{\cdots} O \sim 111-116^{\circ}$ (Table 4). The three acceptors belong to the six-membered ring of tetrahedra juxtapposed to the octahedral sheet (Fig. 1). The other three oxygens sites belonging to the sixmembered ring of tetrahedra appear to be too far from the $\mathrm{H}$ site for a potential $\mathrm{H}$-bond (i.e. O2 $\cdots O$ $\sim 3.6 \AA, H \cdots O \sim 3.02 \AA$, Table 4). The H-bonds are "weak", with unusually low $O-H \cdots O$ angles. The vibrational regime of the proton site appears being only slightly anisotropic; a higher anisotropy is usually observed in dioctahedral phyllosilicates (see Gatta et al. 2011a and references therein).

The HP single-crystal data allowed the description of the elastic behavior of talc up to about $16 \mathrm{GPa}$. The compressional behavior of talc is strongly anisotropic, as observed in other phyllosilicates (e.g. Zanazzi and Pavese 2002 for a review), and is reflected by the axial compressibilities (i.e. $\beta(a): \beta(b): \beta(c)=1.03: 1: 3.15)$ and by magnitude and orientation of the unit-strain ellipsoid (with $\varepsilon_{1}: \varepsilon_{2}: \varepsilon_{3}=1: 1.37: 3.21$ ). The highest compression (i.e. $\varepsilon_{3}$ ) is not observed as perpendicular to the octahedral sheet, as $\varepsilon_{3} \angle a=77.7(6)^{\circ}, \quad \varepsilon_{3} \angle b=89.8(5)^{\circ}$, and $\varepsilon_{3} \angle c$ $=23.4(6)^{\circ}$ (Fig. 1). The lowest compression does not lie on the $a b$-plane (Fig. 1), as $\varepsilon_{1} \angle a=$ $152.7(6)^{\circ}$ (or 27.3(6) $)^{\circ}, \quad \varepsilon_{1} \angle b=64.8(8)^{\circ}$, and $\varepsilon_{1} \angle c=69.1(5)^{\circ}$. We expect that the pronounced compressibility perpendicular to T-O-T layer is mainly accommodated by the inter-layer van der Waals interactions, which are comparatively weaker than the intra-octahedral or intra-tetrahedral covalent/ionic bonds, making the structure significantly less compressible on the $a b$-plane. Not surprisingly, the compressibility along [100] and [010] are almost identical (i.e. $\beta(a): \beta(b)=1.03$ : $1)$.

The isothermal bulk modulus and its $P$-derivatives obtained in this study by M-EoS and IIIBM-EoS fit $\left[\right.$ i.e. M-EoS: $K_{\mathrm{T} 0}=57(3) \mathrm{GPa}$ and $K^{\prime}=4.9(5)$; III-BM-EoS: $K_{\mathrm{T} 0}=56(3) \mathrm{GPa}$ and $K^{\prime}=$ 5.4(7)] differ from those reported by Pawley et al. (1995) [i.e. $K_{\mathrm{T} 0}=41.6(9) \mathrm{GPa}$ and $K^{\prime}=6.5(4)$ ] for a monoclinic polytype of talc $(C 2 / c)$ obtained under hydrostatic conditions ( $P$-medium: methanol:ethanol $=4: 1$ at $P_{\max }=6 \mathrm{GPa}$; Angel et al. 2007, Klotz et al. 2009), though the bulk modulus $P$-derivatives are comparable. The in situ powder experiments performed by Gleason et al. 
(2008) at high pressure (and room- $T$, monoclinic polytype) were performed using ethylcyclohexane or pure water as $P$-transmitting media, or no $P$-medium, even up to $11 \mathrm{GPa}$, under non-hydrostatic conditions. The elastic parameters obtained by III-BM-EoS fit were: $K_{\mathrm{T} 0}=55(5) \mathrm{GPa}$ and $K^{\prime}=14(2)$, with a $P$-medium, and $K_{\mathrm{T} 0}=44(2) \mathrm{GPa}$ and $K^{\prime}=18(2)$, without any $P$-medium. In this case, the bulk modulus obtained from the experiment in which a $P$-medium was used is in good agreement with that obtained in our study. Elastic parameters obtained by BM-EoS fit of $P-V$ data of triclinic talc obtained by ab initio calculation reported by Stixrude (2002) and Mainprice et al. (2008) are: $K_{\mathrm{T} 0}=$ 37.8(4) $\mathrm{GPa}$ and $K^{\prime}=13.6(2)$ and $K_{\mathrm{T} 0}=32.1 \mathrm{GPa}$ and $K^{\prime}=17.4$ ( $e$ sd not given), respectively. The theoretical compressibility obtained by Mainprice et al. (2008) for triclinic and monoclinic polytypes are almost identical.

We believe that the elastic parameters reported on the basis of previous powder diffraction studies might be seriously affected by: 1) the non-hydrostatic regime of the experiments, 2) the grinding-induced strain due to the powder sample preparation, along with 3) the preferred orientations of platy crystallites in the compression chamber of the diamond anvil cell (DAC) and the hydrophobicity of talc (e.g. Duffy and Wang 1998, and references therein). These effects can severely influence the elastic response of talc when compressed in a DAC, and could explain the difference found in bulk moduli [i.e. 41(4) - 55(5) GPa], along with their anomalously high $K^{\prime}$ values [i.e. 6.5(4) - 18(2)], by powder diffraction experiments. The elastic parameters obtained by ab initio calculation show low bulk moduli [i.e. 32.1-37.8 GPa] and high $K$ ' values [i.e. 13.6 17.4]. Our data seem not to fully support these values.

Our experimental data do not show any clear evidence of $P$-induced transformation of talc within the $P$-range investigated. We observe only a slight discontinuity in the $c$ vs. $P$ behaviour at $\sim 7 \mathrm{GPa}$ (somehow reflected also by the $V$ vs. $P$ plot, Fig. 2), likely due to lower precision and accuracy of the unit-cell edge along [001] because the orientation of the crystal in the DAC. Gleason et al. (2008) reported evidence of a $P / T$-induced transformation from talc-I to talc-II at $P \sim 4$ $\mathrm{GPa}$, based on a discontinuity in the axial compressional behaviour. The diffraction pattern of talcII was successfully indexed with the same symmetry of that of talc-I (both monoclinic $C 2 / c$ ). No structural data were provided to support the potential rearrangement at the atomic level, though the authors recalled the experimental finding of Scott et al. (2007), who reported $P$-induced new features in far-infrared spectra of talc, interpreted as iso-symmetrical interlayer adjustments. However, the discontinuity in the compressional behaviour was observed only using pure water as $P$-medium or without any $P$-medium (see Figs. 3 and 4 in Gleason et al. 2008), thus suggesting a change mainly governed by non-hydrostatic regime. Pawley et al. (1995, 2002) performed their 
experiments at hydrostatic pressure in excess of $4 \mathrm{GPa}$ (i.e. up to $6 \mathrm{GPa}$ ), and no clear evidence of discontinuity neither $P$-induced change in the compressional behaviour of talc was observed.

The isothermal bulk modulus of talc and its $P$-derivatives obtained in this study show that the compressibility of talc is similar to that of micas (Zanazzi and Pavese 2002 for a review). The lack of $\mathrm{H} P$ structure refinements prevents the description of the atomic level mechanisms in response to the applied pressure. As highlighted by Gatta et al. (2009, 2010, 2011b, 2012), the ditrigonal distortion is probably the most $P$-induced energy-convenient mechanism in micas to make octahedral- and tetrahedral-sheets match one another so as to form the T-O-T layer. However, such a mechanism is significantly influenced by the presence of an inter-layer cation. Talc cannot simplistically be considered as interlayer-cation-deficient mica. The stacking of the adjacent T-O-T layers in talc is not governed by interlayer cations (or by the energetically-convenient H-bonding configuration) as in micas, but rather by the interplay between repulsive electrostatic and attractive van der Waals forces (Evans and Guggenheim 1988, and references therein). As a consequence, the tetrahedral sites in talc do not superpose over other tetrahedral sites in adjacent layers, as they do in micas, because adjacent T-O-T layers in talc structure are shifted by $\sim 1 / 3 a$ along one of the three pseudo-hexagonal $X$ directions (Bailey 1984). In this light, we cannot predict if in talc the ditrigonal distortion occurs as the main deformation mechanism in response to the applied pressure. If we consider that 1) $\alpha$ is only $4^{\circ}$ in talc at room- $P$ and 2) the bulk modulus $P$-derivative of talc observed in this study is modest, we are not surprised that talc does not experience a $P$-induced amorphization when compressed under hydrostatic condition at least up to $16 \mathrm{GPa}$ (at room- $T$ ).

If we combine the elastic parameters obtained in this study and the thermal data of talc (up to $\sim 1080 \mathrm{~K}$ ) reported by Pawley et al. (1995), a $P-T-V$ EoS of talc can be obtained:

$$
\begin{aligned}
& V_{(P, T)} \sim V_{(P 0, T 0)}[1-\beta \Delta P+\alpha \Delta T]=V_{(P 0, T 0)}\left[1-0.018(1) \cdot \Delta P+2.15(5) \cdot 10^{-5} \cdot \Delta T\right] \\
& \text { (with } \beta=1 / K_{\mathrm{T} 0} \text { in } \mathrm{GPa}^{-1} \text { and } \alpha \text { in } \mathrm{K}^{-1} \text { ). }
\end{aligned}
$$

\section{Acknowledgements}

The authors thank PETRA-III (Hamburg) and ILL (Grenoble) for the allocation of synchrotron and neutron beam time, respectively. S. Nazzareni, an anonymous reviewer and the Editor M. Rieder are thanked. 


\section{References}

Agilent (2012) Xcalibur CCD system, CrysAlis Software system.

Angel RJ (2000) Equation of State. In R.M. Hazen, R.T. Downs, Eds., High-Temperature and High-Pressure Crystal Chemistry, Reviews in Mineralogy and Geochemistry, Vol. 41, pp 35-59. Mineralogical Society of America and Geochemical Society, Washington, DC, U.S.A..

Angel RJ (2001) EOS-FIT V6.0.Computer program (http://www.rossangel.com/).

Angel RJ (2011) Win_Strain V4.11. Computer program (http://www.rossangel.com/).

Angel RJ, Bujak M, Zhao J, Gatta GD, JacobsenSD (2007) Effective hydrostatic limits of pressure media for high-pressure crystallographic studies. J Appl Crystallogr 40:26-32.

Bailey SW (1984) Crystal chemistry of the true micas. In S.W. Bailey, Ed., Micas, Review in Mineralogy, Vol. 13, p. 13-60. Mineralogical Society of America, Washington, DC, U.S.A.

Bailey SW (1988) Introduction; Polytypism of 1:1 layer silicates. In S.W. Bailey, Ed., Hydrous Phyllosilicates (Exclusive of Micas), Review in Mineralogy, Vol. 19, p. 1-27. Mineralogical Society of America, Washington, DC, U.S.A.

Barnes JD, Selverstone J, Sharp ZD (2004) Interactions between serpentinite devolatilization, metasomatism and strike-slip strain localization during deep-crustal shearing in the Eastern Alps. J Metamorphic Geol 22:283-300.

Birch F (1947) Finite elastic strain of cubic crystal. Phys Rev 71:809-824.

Brigatti MF, Guggenheim S (2002) Mica crystal chemistry and the influence of pressure, temperature, and solid solution on atomistic models. In A. Mottana, F.P. Sassi, J.B. Thompson, Jr., S. Guggenheim, Eds., Micas: Crystal Chemistry and Metamorphic Petrology, Review in Mineralogy and Geochemistry, Vol. 46, p. 1-97. Mineralogical Society of America and Geochemical Society, Washington, DC, U.S.A.

Cannat M (1993) Emplacement of mantle rocks in the seafloor at mid-ocean ridges. J Geophys Res 98:4163-4172.

Comodi P, Fumagalli P, Nazzareni S, Zanazzi PF (2005) The $10 \AA$ phase: Crystal structure from single-crystal X-ray data. Am Mineral 90:1012-1016.

Coppens P, Leiserowitz L, Rabinovich D (1965) Calculation of absorption corrections for camera and diffractometer data. Acta Cryst 18:1035-1038.

Chinnery NJ, Pawley AR, Clark SM (1999) In situ observation of the formation of 10 angstrom phase from talc plus $\mathrm{H}_{2} \mathrm{O}$ at mantle pressures and temperatures. Science 286:940-942.

Dellisanti F, Valdrè G (2008) Linear relationship between thermo-dehydroxylation and induced-strain by mechanical processing in vacuum: The case of industrial kaolinite, talc and montmorillonite. Int J Miner Process 88:94-99. 
Dellisanti F, Valdrè G (2010) On the high-temperature structural behaviour of talc $\left(\mathrm{Mg}_{3} \mathrm{Si}_{4} \mathrm{O}_{10}(\mathrm{OH})_{2}\right)$ to $1600^{\circ} \mathrm{C}$ : Effect of mechanical deformation and strain. Phil Mag 90:24432457.

Dellisanti F, Valdrè G, Mondonico M (2009) Changes of the main physical and technological properties of talc due to mechanical strain. Appl Clay Sci 42:398-404.

Ďurovič S, Weiss Z (1983) Polytypism of pyrophyllite and talc. Part I. OD interpretation and MDO polytypes. Silikáty 27:1-8.

Duffy T, Wang Y (1998) Pressure-volume-temperature equations of state. In R.J. Hemley, Ed., Ultrahigh-Pressure Mineralogy: Physics and Chemistry of the Earth's Deep Interior, Review in Mineralogy and Geochemistry, Vol. 37, pp. 425-457. Mineralogical Society of America and Geochemical Society, Washington, DC, U.S.A..

Evans BW, Guggenheim S (1988) Talc, pyrophyllite, and related minerals. In S.W. Bailey, Ed., Hydrous Phyllosilicates (Exclusive of Micas), Review in Mineralogy, Vol. 19, p. 225- 294. Mineralogical Society of America, Washington, DC, U.S.A.

Evans BW, Johannes W, Otterdoom H, Trommsdorff V (1976) Stability of chrysotile and antigorite in the serpentine multisystem. Schweiz Mineral Petrogr Mitt 56:79-93.

Fumagalli P, Stixrude L, Poli S, Snyder D (2001) The 10 angstrom phase: A high-pressure expandable sheet silicate stable during subduction of hydrated lithosphere. Earth Planet Sci Lett 186:125-141.

Gartner Ar, Gartner An (2002) Burgum im schönen Pfitschtal. Tipografia Novaprint Cavalese, 126 pp. .

Gatta GD, Rotiroti N, Pavese A, Lotti P, Curetti N (2009) Structural evolution of a 3T phengite mica up to $10 \mathrm{GPa}$ : an in-situ single-crystal X-ray diffraction study. Z Kristallogr 224:302310.

Gatta GD, Rotiroti N, Pavese A, Lotti P, Curetti N (2010) Structural evolution of a $2 M_{1}$ phengite mica up to $11 \mathrm{GPa}$ : an in-situ single-crystal X-ray diffraction study. Phys Chem Minerals 37:581-591.

Gatta GD, McIntyre GJ, Sassi R, Rotiroti N, Pavese A (2011a) Hydrogen-bond and cation partitioning in $2 M_{1}$-muscovite: A single-crystal neutron-diffraction study at 295 and $20 \mathrm{~K}$. Am Mineral 96:34-41.

Gatta GD, Merlini M, Rotiroti N, Curetti N, Pavese A (2011b) On the crystal chemistry and elastic behavior of a phlogopite 3T. Phys Chem Minerals 38:655-664.

Gatta GD, Merlini M, Liermann H-P, Rothkirch A, Gemmi M. Pavese A (2012) The thermoelastic behavior of clintonite up to $10 \mathrm{GPa}$ and $1,000^{\circ} \mathrm{C}$. Phys Chem Minerals 39:385-397. 
Gleason AE, Parry S,. Pawley A, Jeanloz R, Clark SM (2008) Pressure-temperature studies of talc plus water using X-ray diffraction. Am Mineral 93:1043-1050.

Gruner JW (1934) The crystal structures of talc and pyrophyllite. Z Kristallogr 88:412-419.

Guggenheim S, Eggleton RA (1987) Modulated 2:1 layer silicates: review, systematics, and predictions. Am Mineral 72:724.738.

Guggenheim S, Eggleton RA (1988) Crystal chemistry, classification and identification of modulated layer silicates. In S.W. Bailey, Ed., Hydrous Phyllosilicates (Exclusive of Micas), Vol. 19, p. 675-725. Reviews in Mineralogy, Mineralogical Society of America, Washington, DC, U.S.A.

Hendricks SB (1938) The crystal structure of talc and pyrophyllite. Z Kristallogr 99, 264-274.

Larson AC (1967) Inclusion of secondary extinction in least-squares calculations. Acta Cryst $23: 664-665$.

Howard JAK, Johnson O, Schultz AJ, Stringer AM (1987) Determination of the neutron absorption cross section for hydrogen as a function of wavelength with a pulsed neutron source. J Appl Crystallogr 20:120-122.

Klotz S, Chervin J-C, Munsch P, Le Marchand G (2009) Hydrostatic limits of 11 pressure transmitting media. J. Phys. D (Appl. Phys.) 42:075413.

Lehmann MS, Kuhs W, McIntyre GJ, Wilkinson C, Allibon J (1989) On the use of a small two-dimensional position-sensitive detector in neutron diffraction. J Appl Crystallogr 22:562-568.

Mainprice D, Le Page Y, Rodgers J, Jouanna P (2008) Ab initio elastic properties of talc from 0 to $12 \mathrm{GPa}$ : Interpretation of seismic velocities at mantle pressures and prediction of auxetic behaviour at low pressure. Earth Planet Sc Lett 274:327-338.

Mao HK, Xu J, Bell PM (1986) Calibration of the ruby pressure gauge to $800 \mathrm{kbar}$ under quasihydrostatic conditions. J Geophys Res 91:4673-4676.

Mével C (2003) Serpentinization of abyssal peridotites at mid-ocean ridges. Comptes Rendus Géosciences 335:825-852.

Murnaghan FD (1937) Finite deformations of an elastic solid. Am J Math 49:235-260.

Mysen BO, Ulmer P, Konzett J, Schmidt MW (1998) The upper mantle near convergent plate boundaries. In R.J. Hemley, Ed., Ultrahigh-Pressure Mineralogy: Physics and Chemistry of the Earth's Deep Interior, Review in Mineralogy, Vol. 37, p. 97-138. Mineralogical Society of America, Washington, DC, U.S.A.

Nespolo M, Ferraris G (2001) Effects of the stacking faults on the calculated electron density of mica polytypes - The Ďurovič effect. Eur J Mineral 13:1035-1045. 
Nespolo M, Ďurovič S (2002) Crystallographic basis of polytypism and twinning in micas. In A. Mottana, F.P. Sassi, J.B. Thompson, Jr., S. Guggenheim, Eds., Micas: Crystal Chemistry and Metamorphic Petrology, Review in Mineralogy and Geochemistry, Vol. 46, p. 155-279. Mineralogical Society of America and Geochemical Society, Washington, DC, U.S.A..

Parry SA, Pawley AR, Jones RL, Clark SM (2007) An infrared spectroscopic study of the $\mathrm{OH}$ stretching frequencies of talc and 10- $\AA$ phase to $10 \mathrm{GPa}$. Am Mineral 92:525-531.

Pawley AR, Wood BJ (1995) The high-pressure stability of talc and $10 \AA$ phase: potential storage sites for H2O in subduction zones. Am Mineral 80:998-1003.

Pawley AR, Redfern SAT, Wood BJ (1995) Thermal expansivities and compressibilities of hydrous phases in the system $\mathrm{MgO}-\mathrm{SiO} 2-\mathrm{H} 2 \mathrm{O}$ : Talc, phase A and 10-angstrom phase. Contrib Mineral Petrol 122:301-307.

Pawley AR, Clark SM, Chinnery NJ (2002) Equation of state measurements of chlorite, pyrophyllite, and talc. Am Mineral 87:1172-1182.

Perdikatsis B, Burzlaff $\mathrm{H}$ (1981) Strukturverfeinerung am Talk $\mathrm{Mg}_{3}\left[(\mathrm{OH})_{2} \mathrm{Si}_{4} \mathrm{O}_{10}\right] . \quad \mathrm{Z}$ Kristallogr 156:177-186.

Poli S, Schmidt MW (2002) Petrology of Subducted Slabs. Annual Review of Earth and Planetary Sciences 30:207-235.

Rayner JH, Brown G (1973) The crystal structure of talc. Clays Clay Min 21:103-114.

Robinson K, Gibbs GV, Ribbe PH (1971) Quadratic Elongation: A Quantitative Measure of Distortion in Coordination Polyhedra. Science 172:567-570.

Sears VF.(1986) Neutron Scattering Lengths and Cross-Sections. In K. Sköld and D.L. Price, Eds., Neutron Scattering, Methods of Experimental Physics, Vol. 23A, p. 521-550. Academic Press, New York.

Sheldrick GM (1997) SHELX-97. Programs for crystal structure determination and refinement. University of Göttingen, Germany.

Sheldrick GM (2008) A short history of SHELX. Acta Cryst A64:112-122.

Scott HP, Liu Z, Hemley RJ, and Williams Q (2007) High-pressure infrared spectra of talc and lawsonite. Am Mineral 92:1814-1820.

Stixrude L (2002) Talc under tension and compression: Spinodal instability, elasticity, and structure. J Geophys Res 107-B12:2327.

Trommsdorff V, Sanches-Vizcaino VL, Gomez-Pugnaire MT, and Müntener O (1998) High pressure breakdown of antigorite to spinifex-textured olivine and orthopyroxene, SE Spain. Contrib Mineral Petrol 132:139-148. 
Wilkinson C, Khamis HW, Stansfield RFD, McIntyre GJ (1988) Integration of single-crystal reflections using area multidetectors. J Appl Crystallogr 21:471-478.

Wilson AJC, Prince E. (1999) International Tables for X-ray Crystallography, Volume C: Mathematical, physical and chemical tables (2nd Edition), Kluwer Academic, Dordrecht, NL.

Weiss Z, Ďurovič S (1984) Polytypism of pyrophyllite and talc. Silikáty 28:289-309.

Zanazzi PF, Pavese A (2002) Behavior of micas at high pressure and high temperature. In A. Mottana, F.P. Sassi, J.B. Thompson, Jr., S. Guggenheim, Eds., Micas: Crystal Chemistry and Metamorphic Petrology, Review in Mineralogy and Geochemistry, Vol. 46, p. 99-116. Mineralogical Society of America and Geochemical Society, Washington, DC, U.S.A.. 
Figure 1. (Left side) A view of crystal structure of talc (perpendicular to the ac plane) based on the single-crystal X-ray structure refinement at $223 \mathrm{~K}$ of this study (atomic displacement ellipsoids probability: 99\%), and orientation of the unit-strain ellipsoids with $\Delta P=15.5 \mathrm{GPa}$. (Right side) Hydrogen-bonding scheme in talc structure, based on the neutron structure refinement of this study.
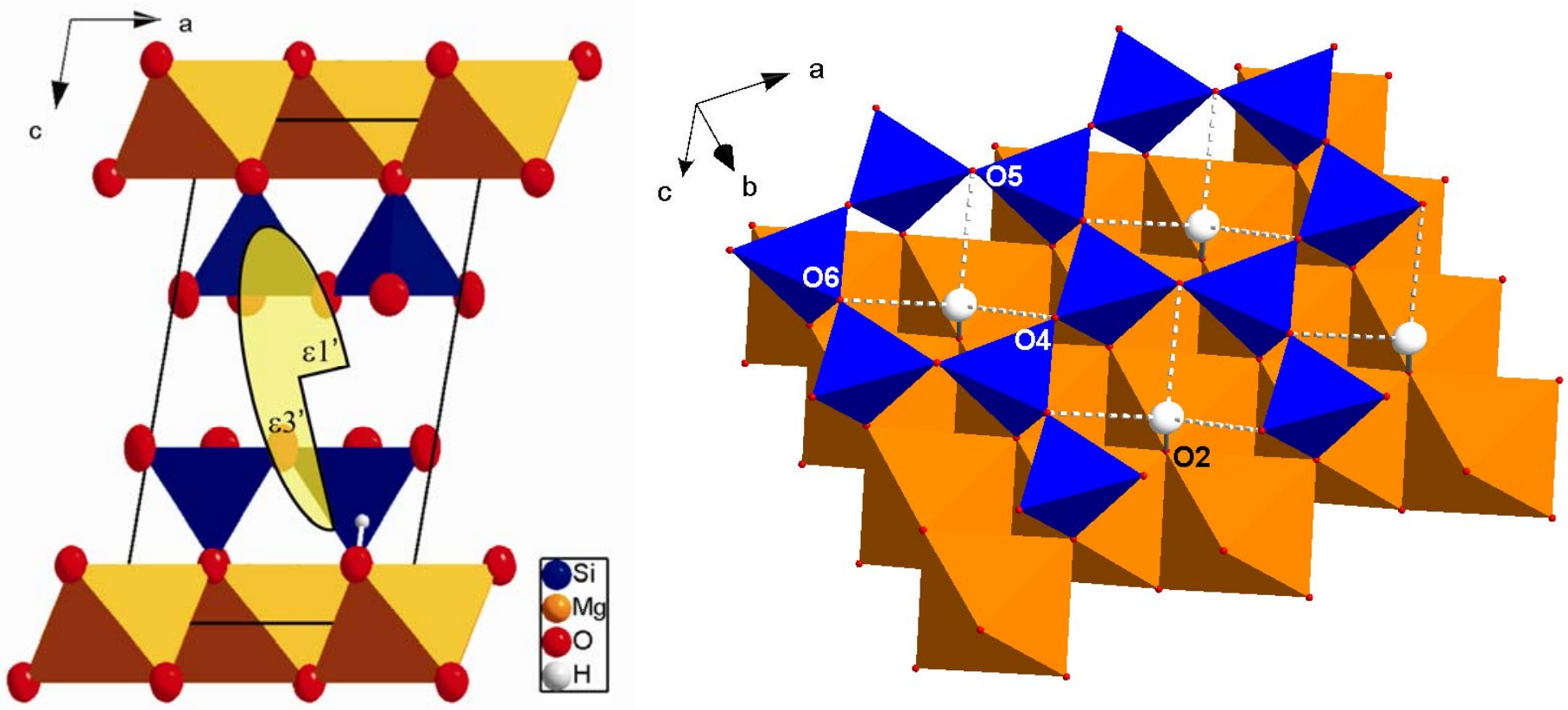
Figure 2. Evolution of the unit-cell constants of talc with pressure; the solid lines represent the BMEoS fit for the $a, b$ and $c$-axis and for the unit-cell volume (see text for details) and the weighted polynomial regression through the data points for the $\alpha, \beta$ and $\gamma$ angles. Evolution of the "normalized stress" $\left(F e=P /\left[3 f e(1+2 f e)^{5 / 2}\right]\right) v s$. Eulerian finite strain $\left(f e=\left[\left(V_{0} / V\right)^{2 / 3}-1\right] / 2\right)$; the solid line is a weighted linear fit through the data.
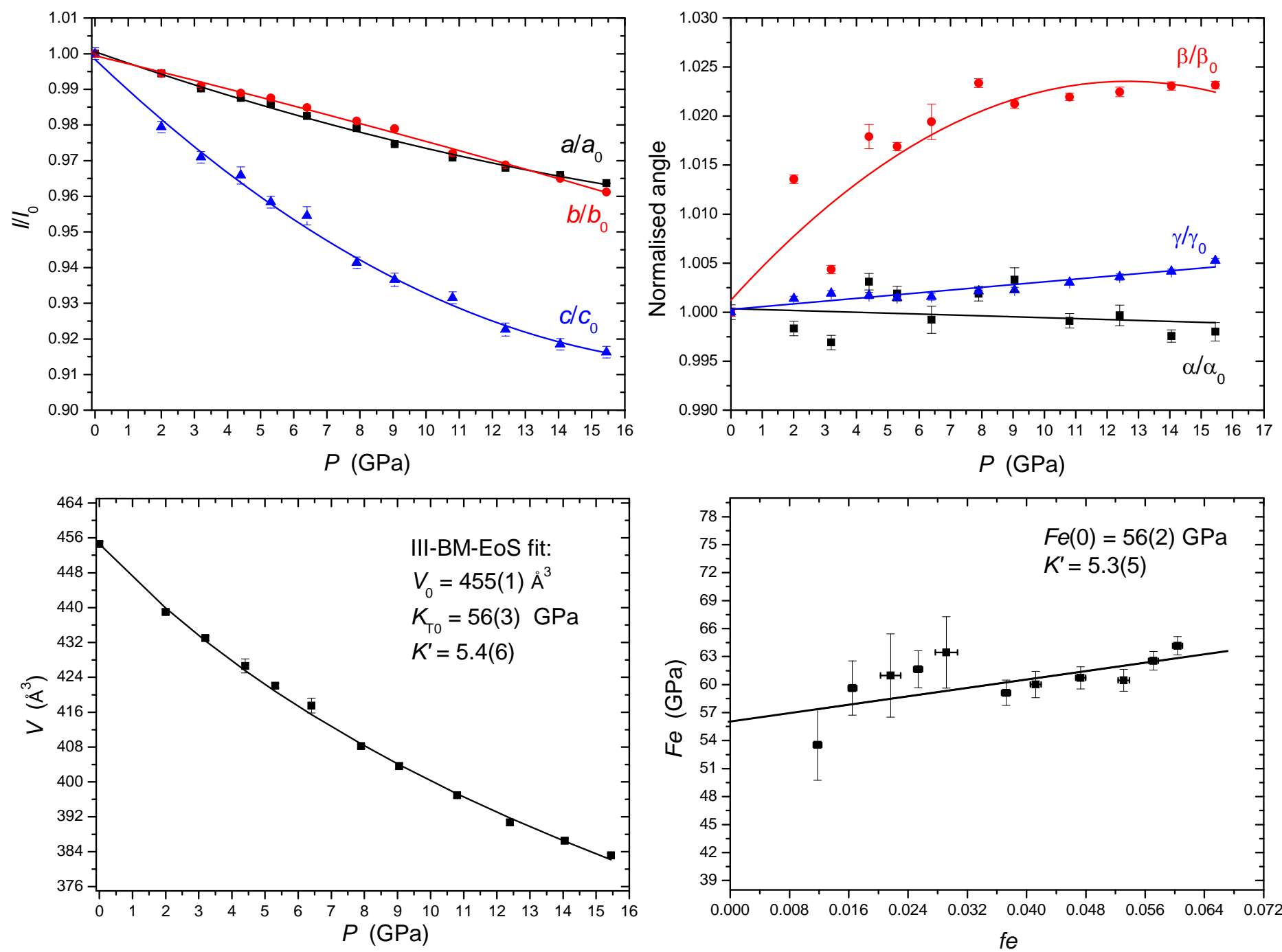
Figure 3. Confidence ellipse at $68.3 \%$ level $\left(\Delta \chi^{2}=2.30, \pm 1 \sigma\right.$, black line $)$, at $95.4 \%$ level $\left(\Delta \chi^{2}=6.17\right.$, $\pm 2 \sigma$, red line) and at $99.73 \%$ level $\left(\Delta \chi^{2}=11.8, \pm 3 \sigma\right.$, green line) obtained from the variancecovariance matrix of $K_{\mathrm{T} 0}$ and $K^{\prime}$ for the BM-EoS fit $\left[\right.$ i.e. $K_{\mathrm{T} 0}=56(3) \mathrm{GPa}$ and $\left.K^{\prime}=5.4(6)\right]$. The $K_{\mathrm{T} 0}$ and $K^{\prime}$ of Pawley et al. (1995) $\left[K_{\mathrm{T} 0}=41.6(9) \mathrm{GPa}\right.$ and $K^{\prime}=6.5(4)$, static compression], Pawley et al. (2002) $\left[K_{\mathrm{T} 0}=41(4) \mathrm{GPa}\right.$ and $K^{\prime}=6(2)$, static compression], Stixrude $(2002)\left[K_{\mathrm{T} 0}=37.8(4) \mathrm{GPa}\right.$ and $K^{\prime}=13.6(2)$, $a b$ initio calculation], Gleason et al. (2008) $\left[K_{\mathrm{T} 0}=55(5) \mathrm{GPa}\right.$ and $K^{\prime}=14(2) ; K_{\mathrm{T} 0}=$ 44(2) GPa and $K^{\prime}=18(1)$; static compression], and Mainprice et al. (2008) $\left[K_{\mathrm{T} 0}=32.1 \mathrm{GPa}\right.$ and $K^{\prime}=17.4$; $a b$ initio calculation] for talc are added for comparison (see text for further details). Error bars: \pm 1 e.s.ds.

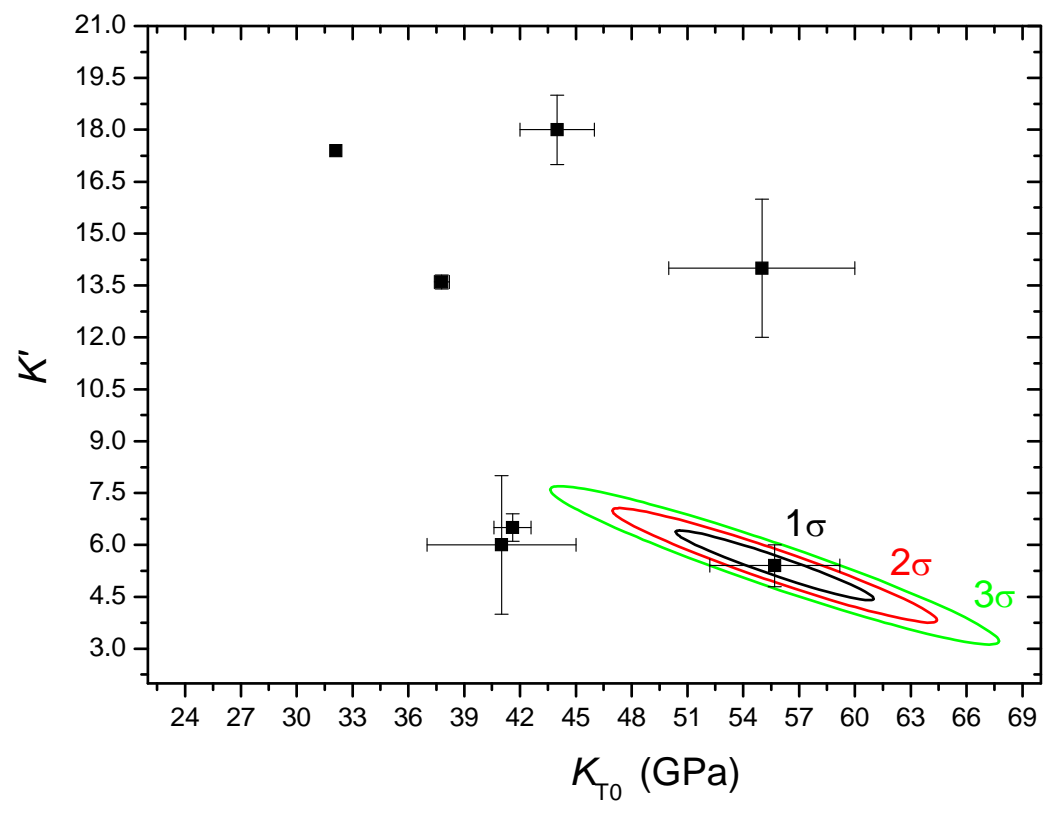


Table 1. Data pertaining to the data collections and structure refinements of talc.

\begin{tabular}{|c|c|c|c|}
\hline$T(\mathrm{~K})$ & 223 & 170 & 20 \\
\hline $\mathrm{X}$-ray radiation & $\mathrm{Mo} K \alpha$ & $\mathrm{MoK \alpha}$ & - \\
\hline Neutron radiation ( $\AA$ ) & - & - & $0.8381(2)$ \\
\hline Reference formula & $\mathrm{Mg}_{3} \mathrm{Si}_{4} \mathrm{O}_{10}(\mathrm{OH})_{2}$ & $\mathrm{Mg}_{3} \mathrm{Si}_{4} \mathrm{O}_{10}(\mathrm{OH})_{2}$ & $\mathrm{Mg}_{3} \mathrm{Si}_{4} \mathrm{O}_{10}(\mathrm{OH})_{2}$ \\
\hline$Z$ & 2 & 2 & 2 \\
\hline Data collection method & $\omega / \varphi$-scans, $1^{\circ} /$ frame, $30 \mathrm{~s} /$ frame & $\omega / \varphi$-scans, $1^{\circ} /$ frame, $30 \mathrm{~s} /$ frame & $\omega-\theta$ scans \\
\hline Space Group & $C \overline{1}$ & $C \overline{1}$ & $C \overline{1}$ \\
\hline$a(\AA)$ & $5.2905(7)$ & $5.2908(6)$ & $5.299(3)$ \\
\hline$b(\AA)$ & $9.1739(11)$ & $9.1719(8)$ & $9.165(4)$ \\
\hline$c(\AA)$ & $9.4850(16)$ & $9.4746(14)$ & $9.484(7)$ \\
\hline$\alpha\left({ }^{\circ}\right)$ & $90.910(12)$ & $91.006(9)$ & $90.76(5)$ \\
\hline$\beta\left(^{\circ}\right)$ & $99.640(13)$ & $99.742(11)$ & $100.39(5)$ \\
\hline$\gamma\left({ }^{\circ}\right)$ & $90.101(11)$ & $90.113(8)$ & $90.16(4)$ \\
\hline Maximum $2 \theta\left(^{\circ}\right)$ & 70 & 70 & 61 \\
\hline Measured reflections & 3011 & 2994 & 791 \\
\hline Unique reflections & 1946 & 1934 & 675 \\
\hline Unique reflections with $F_{0}>4 \sigma\left(F_{0}\right)$ & 1755 & 1750 & 635 \\
\hline$R_{\text {int }}$ & 0.0275 & 0.0262 & 0.0528 \\
\hline N. of refined parameters & 96 & 96 & 42 \\
\hline$R_{1}, F_{0}>4 \sigma\left(F_{0}\right)$ & 0.0742 & 0.0755 & 0.1431 \\
\hline $\mathrm{w} R^{2}$ & 0.1393 & 0.1409 & 0.1703 \\
\hline Residuals $\left(e^{-} / \AA^{3}, \mathrm{fm} / \AA^{3}\right)$ & $+2.0 /-1.3$ & $+2.2 /-1.3$ & $+3.2 /-2.7$ \\
\hline
\end{tabular}


Table 2. Atomic coordinates and displacement parameters $\left(\AA^{2}\right)$ of talc (XSR: X-ray structure refinement; NSR: neutron structure refinement). $U_{e q}$ is defined as one third of the trace of the orthogonalised $U_{i j}$ tensor.

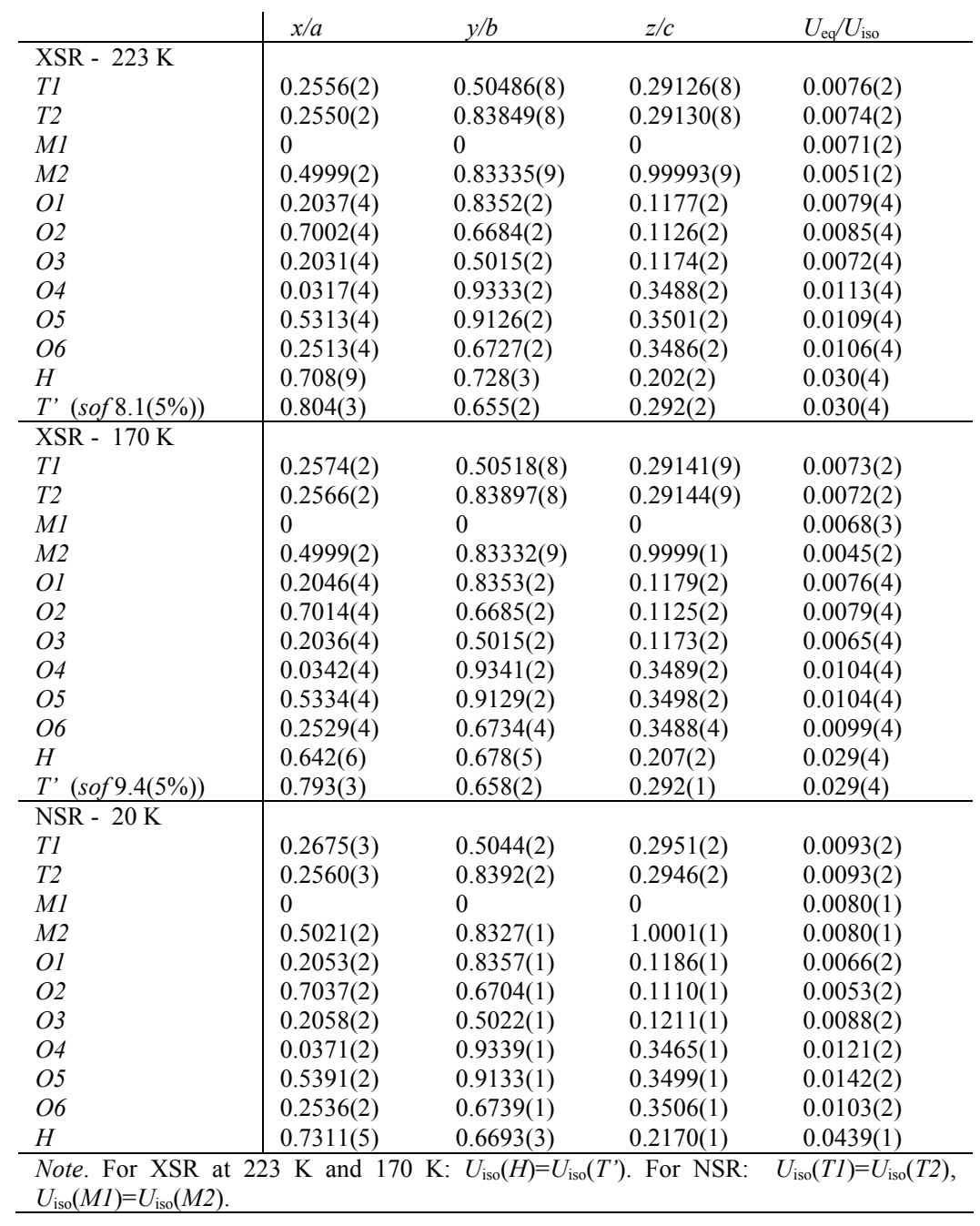


Table 3. Refined displacement parameters $\left(\AA^{2}\right)$ in the expression: $-2 \pi^{2}\left[\left(h a^{*}\right)^{2} U_{11}+\ldots+2 h k a^{*} b^{*} U_{12}\right.$ $\left.+\ldots+2 k l b * c^{*} U_{23}\right]$ (XSR: X-ray structure refinement; NSR: neutron structure refinement).

\begin{tabular}{l|lllllll} 
& & $U_{11}$ & $U_{22}$ & $U_{33}$ & $U_{23}$ & $U_{13}$ & $U_{12}$ \\
\hline XSR - 223 K & $T 1$ & $0.0064(3)$ & $0.0043(3)$ & $0.0123(3)$ & $0.0009(2)$ & $0.0019(3)$ & $-0.0004(2)$ \\
& $T 2$ & $0.0052(3)$ & $0.0042(3)$ & $0.0128(3)$ & $0.0007(2)$ & $0.0019(3)$ & $0.0008(2)$ \\
& $M 1$ & $0.0055(6)$ & $0.0042(5)$ & $0.0117(6)$ & $0.0013(4)$ & $0.0017(4)$ & $0.0001(4)$ \\
& $M 2$ & $0.0035(4)$ & $0.0020(4)$ & $0.0099(4)$ & $0.0007(3)$ & $0.0014(3)$ & $-0.0005(3)$ \\
& $O 1$ & $0.0077(9)$ & $0.0053(8)$ & $0.0106(8)$ & $0.0002(6)$ & $0.0012(7)$ & $0.0011(6)$ \\
& O2 & $0.0090(9)$ & $0.0059(8)$ & $0.0107(8)$ & $0.0002(6)$ & $0.0021(7)$ & $0.0008(7)$ \\
& O3 & $0.0060(9)$ & $0.0046(8)$ & $0.0112(8)$ & $0.0012(6)$ & $0.0019(7)$ & $-0.0005(6)$ \\
& O4 & $0.0078(9)$ & $0.0089(8)$ & $0.0173(9)$ & $0.0010(7)$ & $0.0026(7)$ & $0.0042(7)$ \\
& $O 5$ & $0.0067(9)$ & $0.0109(9)$ & $0.0152(9)$ & $0.0009(7)$ & $0.0020(7)$ & $-0.0012(7)$ \\
& $O 6$ & $0.0120(10)$ & $0.0056(8)$ & $0.0142(9)$ & $0.0007(7)$ & $0.0020(8)$ & $0.0022(7)$ \\
\hline XSR - 170 K & $T 1$ & $0.0062(4)$ & $0.0040(3)$ & $0.0116(4)$ & $0.0005(3)$ & $0.0014(3)$ & $-0.0009(3)$ \\
& $T 2$ & $0.0054(4)$ & $0.0041(3)$ & $0.0121(4)$ & $0.0005(3)$ & $0.0017(3)$ & $0.0004(3)$ \\
& $M 1$ & $0.0054(6)$ & $0.0038(5)$ & $0.0114(6)$ & $0.0007(4)$ & $0.0021(5)$ & $-0.0006(4)$ \\
& $M 2$ & $0.0027(4)$ & $0.0026(4)$ & $0.0084(4)$ & $0.0004(3)$ & $0.0012(3)$ & $-0.0011(3)$ \\
& $O 1$ & $0.0079(9)$ & $0.0050(8)$ & $0.0097(9)$ & $0.0004(6)$ & $0.0010(7)$ & $0.0006(7)$ \\
& $O 2$ & $0.0079(9)$ & $0.0054(8)$ & $0.0104(9)$ & $0.0002(6)$ & $0.0019(7)$ & $0.0001(7)$ \\
& $O 3$ & $0.0056(9)$ & $0.0039(8)$ & $0.0100(9)$ & $0.0014(6)$ & $0.0013(7)$ & $-0.0006(7)$ \\
& $O 4$ & $0.0076(9)$ & $0.0076(9)$ & $0.0165(10)$ & $0.0005(7)$ & $0.0029(8)$ & $0.0032(7)$ \\
& $O 5$ & $0.0069(9)$ & $0.0086(9)$ & $0.0156(10)$ & $0.0005(7)$ & $0.0017(8)$ & $-0.0015(7)$ \\
& $O 6$ & $0.0112(10)$ & $0.0046(8)$ & $0.0138(10)$ & $0.0001(7)$ & $0.0017(8)$ & $0.0014(7)$ \\
\hline NSR - 20 K & $H$ & $0.061(1)$ & $0.039(1)$ & $0.032(1)$ & $0.010(1)$ & $0.008(1)$ & $-0.004(1)$ \\
\hline
\end{tabular}


Table 4. Bond distances $(\AA)$, polyhedral volumes $\left(\AA^{3}\right)$, ditrigonal distortion angle $\left(\alpha,{ }^{\circ}\right)$ and other structural parameters based on X-ray and neutron structure refinements.

\begin{tabular}{|c|c|c|c|}
\hline & XSR - $223 \mathrm{~K}$ & XSR - $170 \mathrm{~K}$ & NSR - $20 \mathrm{~K}$ \\
\hline T1-O4 & $1.616(2)$ & $1.616(2)$ & $1.566(2)$ \\
\hline T1-O3 & $1.626(2)$ & $1.626(2)$ & $1.623(2)$ \\
\hline T1-O6 & $1.627(2)$ & $1.628(2)$ & $1.639(2)$ \\
\hline T1-O5 & $1.634(2)$ & $1.631(2)$ & $1.631(2)$ \\
\hline$<T 1-O\rangle$ & 1.6252 & 1.6253 & 1.6148 \\
\hline M.P.Q.E & 1.0000 & 1.0000 & 1.0014 \\
\hline A.V. & 0.071 & 0.086 & 5.018 \\
\hline$V(T 1)$ & 2.20 & 2.20 & 2.16 \\
\hline$T 2-O 5$ & $1.619(2)$ & $1.619(2)$ & $1.637(2)$ \\
\hline$T 2-O 1$ & $1.623(2)$ & $1.620(2)$ & $1.643(2)$ \\
\hline$T 2-O 6$ & $1.624(2)$ & $1.623(2)$ & $1.613(2)$ \\
\hline$T 2-O 4$ & $1.629(2)$ & $1.627(2)$ & $1.592(2)$ \\
\hline$<T 2-O\rangle$ & 1.624 & 1.622 & 1.621 \\
\hline M.P.Q.E & 1.0000 & 1.0000 & 1.0006 \\
\hline A.V. & 0.055 & 0.056 & 1.976 \\
\hline$V(T 2)$ & 2.20 & 2.19 & 2.19 \\
\hline$M 1-O 2($ x 2$)$ & $2.052(2)$ & $2.052(2)$ & $2.060(2)$ \\
\hline$M 1-O 3(\mathrm{x} 2)$ & $2.072(2)$ & $2.070(2)$ & $2.094(2)$ \\
\hline$M 1-O 1$ ( $\mathrm{x} 2)$ & $2.086(2)$ & $2.087(2)$ & $2.080(2)$ \\
\hline$<M 1-O>$ & 2.070 & 2.070 & 2.078 \\
\hline M.P.Q.E & 1.0086 & 1.0089 & 1.0083 \\
\hline A.V. & 28.492 & 29.237 & 27.613 \\
\hline$V(M 1)$ & 11.67 & 11.67 & 11.82 \\
\hline$M 2-O 2$ & $2.055(2)$ & $2.049(2)$ & $2.026(2)$ \\
\hline$M 2-O 2$, & $2.057(2)$ & $2.059(2)$ & $2.030(2)$ \\
\hline$M 2-O 1$ & $2.072(2)$ & $2.069(2)$ & $2.085(2)$ \\
\hline $\mathrm{M} 2-\mathrm{Ol}$, & $2.082(2)$ & $2.082(2)$ & $2.090(2)$ \\
\hline$M 2-O 3$ & $2.077(2)$ & $2.075(2)$ & $2.095(2)$ \\
\hline$M 2-O 3$ & $2.085(2)$ & $2.085(2)$ & $2.102(2)$ \\
\hline$<M 2-O>$ & 2.071 & 2.070 & 2.071 \\
\hline M.P.Q.E & 1.0087 & 1.0089 & 1.0081 \\
\hline A.V. & 28.970 & 29.412 & 26.556 \\
\hline$V(M 2)$ & 11.69 & 11.67 & 11.71 \\
\hline $\mathrm{O} 2-\mathrm{H}$ & $0.997(12)$ & $0.998(11)$ & $0.990(1)$ \\
\hline$O 2 \cdots O 4$ & & & $3.514(3)$ \\
\hline$H^{\cdots O O 4}$ & & & $3.032(3)$ \\
\hline $\mathrm{O} 2-\mathrm{H}^{\cdots} \mathrm{O}$ & & & $111.2(1)$ \\
\hline $\mathrm{O} 2 \cdots \mathrm{O}^{\prime}$ & & & $3.360(2)$ \\
\hline$H^{\cdots} \mathrm{O}^{\prime}$ & & & $2.780(3)$ \\
\hline$O 2-H^{\cdots} O 4^{\prime}$ & & & $118.0(1)$ \\
\hline$O 2 \cdots O 5$ & & & $3.542(3)$ \\
\hline$H^{\cdots} \mathrm{O} 5$ & & & $3.018(2)$ \\
\hline$O 2-H^{\cdots} O 5$ & & & $114.3(1)$ \\
\hline $\mathrm{O} 2 \cdots \mathrm{O}^{\prime}$ & & & $3.382(2)$ \\
\hline$H^{\cdots} \mathrm{O} 5^{\prime}$ & & & $2.831(2)$ \\
\hline$O 2-H^{\cdots} O 5^{\prime}$ & & & $115.8(1)$ \\
\hline$O 2 \cdots O 6$ & & & $3.575(3)$ \\
\hline$H^{\cdots} \mathrm{O}$ & & & $3.023(3)$ \\
\hline $\mathrm{O} 2-\mathrm{H}^{\cdots} \mathrm{O} \mathrm{O}$ & & & $116.4(1)$ \\
\hline $\mathrm{O} 2 \cdots \mathrm{O} 6^{\prime}$ & & & $3.352(3)$ \\
\hline$H^{\cdots} O 6^{\prime}$ & & & $2.825(3)$ \\
\hline$\alpha$ & $4.0(1)$ & 4.1(1) & $4.4(1)$ \\
\hline
\end{tabular}

Note: $\alpha=1 / 6 \cdot \sum_{i=1}^{6}\left|120^{\circ}-\varphi_{i}\right| / 2$, where $\varphi_{\mathrm{i}}$ is the angle between basal

edge of neighbouring tetrahedra articulated in the $6 \mathrm{mR}$ (Brigatti and Guggenheim 2002). M..P.Q.E. is the "mean polyhedral quadratic elongation" and A.V. is the "angular variance" as defined by Robinson et al. (1971). 
Table 5. Unit-cell constants of talc at different pressures.

\begin{tabular}{l|lllllll}
$P(\mathrm{GPa})$ & $a(\AA)$ & $b(\AA)$ & $c(\AA)$ & $\alpha\left(^{\circ}\right)$ & $\beta\left(^{\circ}\right)$ & $\gamma\left({ }^{\circ}\right)$ & $V\left(\AA^{3}\right)$ \\
\hline 0.0001 & $5.3047(3)$ & $9.195(1)$ & $9.434(11)$ & $90.38(6)$ & $98.87(4)$ & $90.11(2)$ & $454.6(5)$ \\
$2.0(1)$ & $5.2754(4)$ & $9.144(1)$ & $9.240(11)$ & $90.23(6)$ & $100.21(4)$ & $90.23(2)$ & $439.0(5)$ \\
$3.2(1)$ & $5.2530(4)$ & $9.112(1)$ & $9.160(11)$ & $90.10(6)$ & $99.30(4)$ & $90.28(2)$ & $433.0(5)$ \\
$4.4(1)$ & $5.2390(6)$ & $9.093(1)$ & $9.110(20)$ & $90.66(7)$ & $100.64(12)$ & $90.26(3)$ & $426.6(16)$ \\
$5.3(1)$ & $5.2300(4)$ & $9.081(1)$ & $9.041(11)$ & $90.55(6)$ & $100.54(4)$ & $90.24(2)$ & $422.1(5)$ \\
$6.4(1)$ & $5.2120(6)$ & $9.056(1)$ & $9.005(22)$ & $90.31(9)$ & $100.79(18)$ & $90.25(3)$ & $417.5(17)$ \\
$7.9(1)$ & $5.1940(4)$ & $9.021(1)$ & $8.881(11)$ & $90.55(6)$ & $101.18(4)$ & $90.30(2)$ & $408.2(5)$ \\
$9.1(1)$ & $5.1700(3)$ & $9.002(1)$ & $8.836(14)$ & $90.68(9)$ & $100.97(4)$ & $90.31(2)$ & $403.7(7)$ \\
$10.8(1)$ & $5.1500(3)$ & $8.938(1)$ & $8.788(12)$ & $90.30(6)$ & $101.04(3)$ & $90.38(2)$ & $396.9(6)$ \\
$12.4(1)$ & $5.1350(3)$ & $8.908(1)$ & $8.704(14)$ & $90.35(9)$ & $101.09(4)$ & $90.43(3)$ & $390.7(7)$ \\
$14.1(1)$ & $5.1240(3)$ & $8.873(1)$ & $8.665(12)$ & $90.16(5)$ & $101.15(4)$ & $90.48(2)$ & $386.5(5)$ \\
$15.5(1)$ & $5.1120(3)$ & $8.838(1)$ & $8.644(12)$ & $90.20(8)$ & $101.16(3)$ & $90.58(2)$ & $383.2(5)$ \\
\hline
\end{tabular}

